\title{
Memórias e identidades: a patrimonialização e os usos do passado ${ }^{1}$
}

Sandra Pelegrini*

Resumo: O presente artigo, instigado pelas proposições do dossiê "História e Patrimônio: questões teóricas e metodológicas”, efetua a análise do conceito de patrimonialização e da invenção de espaços de memória, associados às políticas públicas de proteção dos bens culturais e do turismo. Para tanto, busca, por um lado, detectar os perigos que cercam os profissionais das Ciências Humanas e das Ciências Sociais e Aplicadas que atuam em comissões ou conselhos que visam a salvaguarda dos bens patrimoniais. E, por outro, estabelece as conexões teóricas e metodológicas que visam problematizar a questão do tombamento e do registro de bens patrimoniais, na Estância Balnearia de São Vicente, localizada no litoral de São Paulo/Brasil. A opção pelo debate epistemológico articulado ao empírico é relevante, pois oferece subsídios para as reflexões sobre a responsabilidade social dos pesquisadores que integram tais comissões e conselhos, aos quais é instituído o poder de decisão para eleger um bem patrimonial ou condená-lo ao esquecimento e à destruição.

Palavras-chave: Patrimonialização. Políticas públicas. Espaços de memória.

\footnotetext{
"Professora na Universidade Estadual de Maringá (UEM).

Doutorado em História Social pela Universidade de São Paulo (USP).

E-mail: sandrapelegrini@yahoo.com.br
} 
Os anseios pela patrimonialização tem se intensificado no século XXI e, como tal, tem nos colocado diante do acirramento das disputas pela memória e das reinvindicações de diversos grupos e/ou etnias que clamam pelo reconhecimento de seus bens e tradições culturais, tomados como representações identitárias. Tais demandas tornam evidentes as correlações de forças entre os gestores públicos e os grupos que bradam pela distinção de seus acervos, de bens tangíveis e intangíveis. $\mathrm{Na}$ esteira desses processos de patrimonialização, constatamos o quão vigorosos podem ser os embates na esfera da construção da narrativa histórica e das ações em prol da salvaguarda do patrimônio, uma vez que envolvem os usos do passado, empoderamento e invenções.

Diante do exposto, parece-nos explicitada a complexidade das variáveis a serem observadas quando tratamos da salvaguarda de bens patrimoniais, e ainda, que a lida dessa problemática exige reflexões no âmbito epistemológico, sem que o empírico seja negligenciado, de modo a evitarmos incorrer no erro de tornar inócuas estas ponderações. Portanto, para que as nossas proposições teóricas e metodológicas se tornem compreensíveis e para que, de alguma maneira, contribuam para a elucidação de problemas nesta seara, consideramos condição crucial agregarmos um estudo de caso ao debate epistemológico.

Ao fazê-lo estaremos enfrentando questões atinentes ao debate teórico e ofereceremos subsídios para que os professores se sintam estimulados a relacionar o ensino de história com as temáticas do patrimônio (e vice-versa). Ademais, instigaremos a percepção das relações de ensino-aprendizagem como locus privilegiado de ações multiplicadoras que podem contribuir para o despertar da consciência da preservação entre crianças, jovens e adultos e incitá-los ao exercício de seu direito à memória.

Nos limiares do século XXI, a responsabilidade social dos profissionais que se dedicam aos estudos e pesquisas do patrimônio ou a gestão de acervos em espaços museais institucionais ou comunitários, vai além das elucubrações teóricas. Sem dúvida, essa responsabilidade exige desses profissionais experiências investigativas e atividades de campo. Postas essas preliminares, ressaltamos a 
relevância das articulações entre teoria, metodologia e empirismo. Nessa linha de interpretação, passamos a discutir o conceito de patrimonialização e suas interfaces com as políticas de proteção, na sequência, tratamos das investidas das autoridades políticas da cidade de São Vicente, localizada no litoral de São Paulo (Brasil) e das ações do seu conselho municipal de defesa do patrimônio histórico, artístico, arquitetônico, cultural e turístico.

\section{A patrimonialização e as políticas públicas de proteção dos bens culturais}

$\mathrm{O}$ ato de patrimonializar implica conferir o estatuto de patrimônio para um bem material ou imaterial, a partir do reconhecimento de seu valor identitário, histórico, representativo de tradições culturais, entre outras singularidades que possam ser reconhecidas nos modos de viver de um grupo radicado em um determinado espaço e temporalidade. Portanto, o reconhecimento dos bens patrimoniais pressupõe uma tomada de decisão que visa garantir a sua proteção, conservação e preservação por intermédio de instrumentos legais (decretos e leis), que viabilizem o registro ou o tombamento, dependendo da tipologia do bem.

Nesse processo, parece-nos que caberia ao pesquisador, vinculado à área das Ciências Humanas e/ou das Ciências Sociais Aplicadas, contribuir para a valorização do patrimônio, independentemente de suas crenças pessoais; auxiliar os grupos reivindicantes a organizar um inventário de tais bens (identificados principalmente por seu valor de representatividade) que subsidiará a implementação da lei ou o decreto-lei de tombamento ou registro.

Mas, ao tratar dos enredos da patrimonialização, esse profissional deve se precaver das armadilhas que, não raro, aparecem quando pensamos os bens culturais ou naturais a partir de visões utópicas e até simplórias. A primeira delas, recorrente entre os pesquisadores iniciantes, refere-se às limitações das ações do estudioso que não tem o poder de salvaguardar um bem patrimonial de um 
grupo, pois ele só será preservado se os membros da comunidade o reconhecerem como tal e se expressarem o sentido de pertencimento. A segunda insídia a ser driblada é aquela que diz respeito à aplicação das recomendações dos organismos internacionais, uma vez que não podem ser aplicadas indiscriminadamente e de modo universalizante.

Talvez a mais perniciosa de todas as armadilhas centre-se no perigo do próprio pesquisador contribuir para dissimular os embates pela memória e as disputas em jogo, uma vez que os experts, aqueles que por meio do discurso da competência, decidem o que será ou não eleito como bem patrimonial local, estadual, nacional e, quiçá, um patrimônio da humanidade, pois podem manifestar dificuldade de escapar da teia de interesses que envolve o financiamento de suas próprias pesquisas.

Ademais, os postulados que informam as políticas públicas de proteção dos bens patrimoniais em distintos espaços territoriais do planeta são mediados por recomendações de instituições que normatizam as relações diplomáticas e financeiras em tempos de guerra e paz, escassez e fartura. Assim sendo, não podemos negligenciar também o fato de que órgãos como a Organização das Nações Unidas (ONU), a Organização das Nações Unidas para a Educação, Ciência e Cultura (Unesco) e o Conselho Internacional de Museus $(\mathrm{ICOM})^{2}$ formulam critérios que orientam os países signatários e oficialmente procuram não ferir interesses relativos à segurança, às transações políticas e econômicas. No entanto, apesar do respeito que devemos a tais instituições e aos seus respectivos líderes, especialistas de renome entre seus pares, nós sabemos que não são isentos e que estão à mercê de diversas potências mundiais.

É preciso termos clareza quanto aos níveis de interferência que organismos como a ONU, a Unesco e o ICOM, apenas para citar os mais conhecidos e prestigiados, podem exercer. Será que os seus experts estão atentos ao fato de que algumas dessas premissas mundiais não atendem as necessidades de reconhecimento dos bens patrimoniais de coletividades com tradições culturais diferentes das ocidentais? Questão de difícil resposta, mas é certo que esses órgãos são capazes reunir livres pensadores para mediar conflitos e que 
lideram estruturas representativas, responsáveis pelo contato com autoridades políticas internacionais, nacionais, estaduais, regionais e locais. Eles, entre outras inúmeras incumbências e competências, conseguem organizar eventos que congregam tanto políticos com significativo poder de decisão, como membros da sociedade civil oriundos de diversos países do mundo, das nações mais abastadas às mais miseráveis.

Os institutos de defesa do patrimônio e dos museus, por sua vez, também possuem representações na esfera nacional e estadual nos países que são signatários desses órgãos. No Brasil, os institutos do Patrimônio Histórico e Artístico Nacional (IPHAN) e de Museus (Ibram), por exemplo, seguem as recomendações dos organismos supracitados.

Por estas e outras razões, as políticas públicas de proteção enfrentam muitos desafios no âmbito do tombamento dos bens materiais e, sobretudo, no âmbito do registro dos bens culturais imateriais e naturais. Se os decretos oficiais são implementados primeiramente nas instâncias locais de poder, ou seja, nos municípios ou nas províncias, torna-se urgente reconhecermos os enfrentamentos ocorridos entre os atores sociais em termos gerenciais e no campo das disputas pela memória.

A memória coletiva constitui, como assevera Le Goff, um elemento-chave na construção identitária individual ou dos grupos, uma vez que figura como "um instrumento e um objeto de poder" (1996, p. 476). Se a noção de memória não existe sem a de identidade e a de lembrança sem a de esquecimento, como assinala Candau (2011; 2016), são justamente nos campos de disputas pelas memórias que as identidades se fortalecem e se impõem sobre as demais. Além disso, como ferramentas do poder instituído, as memórias e as construções identitárias são referências presentes no embasamento e na aplicação das políticas públicas em diversos níveis.

Em termos gerenciais, quando focadas na promoção do desenvolvimento econômico e social, as autoridades políticas municipais articulam suas ações envolvendo, simultaneamente, várias secretarias. Aliás, segundo especialistas como Choay (2001), Canclini (2006; 2015) e Jacobi (2005), as políticas públicas em prol do patrimônio 
são bem sucedidas na medida em que se desenvolvem a partir do trabalho articulado e estruturado entre as secretarias municipais de Cultura, Educação, Desenvolvimento Econômico, Fazenda, Lazer/Esporte, Meio Ambiente, Mobilidade Urbana/Transportes, Obras, Turismo, entre outras pastas e, em particular, entre aquelas direcionadas à inclusão de jovens e idosos em situação de risco, à promoção e ao respeito à diversidade étnica e de gênero.

Essa definição de políticas públicas articuladas aproxima-se da noção de "desenvolvimento sustentável" que, segundo Jacobi, "apesar das críticas a que tem sido sujeita", vem sendo "quase universalmente aceita", porque delimita as possibilidades de crescimento e oferece visibilidade para a "luta política" em vários sentidos, "além de servir como argumentação para as políticas de proteção dos bens patrimoniais e ambientais (2005, p. 238). Num espectro mais amplo, a definição de desenvolvimento vem sendo objeto de celeumas, porque não se aceita mais que esta acepção seja tomada apenas como sinônimos do crescimento econômico (2005, p. 235). A "nova" noção de desenvolvimento nos remete à redefinição das "relações entre sociedade humana e natureza", o que implica também a "uma mudança substancial do próprio processo civilizatório" e fortalece os argumentos em prol da ideia "co-responsabilização" dos cidadãos (2005, p. 238).

Ora, nas secretarias de Cultura e/ou Educação, por vezes, acopladas às secretarias de Turismo, são criadas as Comissões de Patrimônio que tendem a integrar os saberes e fazeres de historiadores de ofício e gestores de museus, de antropólogos e arquitetos, de membros de associações comerciais e industriais, de representantes das câmaras de vereadores e das universidades públicas e privadas (PELEGRINI, 2010; 2017).

Ora, essas comissões figuram como lugares de disputas pelas memórias! Logo, retornamos aos principais problemas levantados nas preliminares desse artigo: ao de que os membros dos conselhos de patrimônio, aos quais é instituído o poder de decisão para eleger um bem patrimonial (ou condená-lo ao esquecimento e a destruição) não são isentos e que deveriam estar atentos aos reclamos de 
distintas comunidades, por conseguinte, não deveriam atender apenas as demandas das elites locais.

Nessa linha de argumentação, nós constatamos outros impasses: essas comissões estão preparadas para dar conta das questões que envolvem a patrimonialização? Seus membros conseguem apreender a importância das tradições culturais populares e distinguir as múltiplas manifestações da cultura ocidental, representadas nos monumentos aos desbravadores, nas efemérides e nos marcos da história oficial? As políticas de proteção dos bens patrimoniais efetivamente respeitam os vínculos identitários, cruciais para a preservação das memórias, para a salvaguarda das distintas tipologias de bens culturais e naturais vinculadas às práticas costumeiras de grupos diversos, independentemente de seu lugar de origem?

Não temos a pretensão de responder as indagações ora formuladas, porém, a formulação delas nos ajuda a reiterar que esses processos são permeados por tensões motivadas por especificidades locais, rivalidades entre lideranças comunitárias, grupos étnicos e políticos. Para melhor explicitarmos como se dão tais conflitos e como são gerenciados, entendemos ser elucidativo apresentarmos alguns aspectos da trajetória de patrimonialização na cidade de São Vicente, localizada no litoral sul do estado de São Paulo, na região Sudeste do Brasil ${ }^{3}$.

Esta estância balneária apresenta algumas peculiaridades que a tornam especial nessa reflexão, porque as relações de pertencimento da população residente foram construídas a partir da disseminação de discursos sobre a sua "vocação histórica", uma vez que a cidade é considerada a mais antiga do Brasil e apresenta características geográficas e históricas que foram reconhecidos pelas autoridades locais como bens patrimoniais que poderiam promover o desenvolvimento turístico, social e econômico dos munícipes.

Laços de pertença que, em última instância, foram edificados a despeito das controvérsias historiográficas e estão embasados no enaltecimento da figura de Martim Afonso de Souza como fundador da primeira cidade brasileira, cuja esquadra teria ancorado na ilha de São Vicente no século XVI, enfrentado contínuos confrontos com a população indígena, em especial, os Carijós, Tamoios e Guaianases;

Anos 90, Porto Alegre, v. 25, n. 48, p. 87-115, dez. 2018 
desenvolvido atividades exploratórias nessas águas e no rio da Prata; oportunizado a instalação de instituições representativas do poder real (igreja, pelourinho e câmara); introduzido a agricultura de subsistência e a cultura da cana-de-açúcar e os mecanismos necessários para a sua manufatura (GIANESELLA, 2012).

Ao herói e desbravador é acrescentado o vigor "rebelde", reforçado na imagem de um homem que, mesmo sem integrar oficialmente o plano de colonização da coroa portuguesa, teria resguardado o litoral brasileiro das invasões com o apoio dos aventureiros arrebatados pelo desejo do enriquecimento; aberto o caminho para a ocupação do litoral e colaborado indiretamente para a implantação do projeto agrário exportador, implementado por séculos em toda a Colônia. Ademais, teria sido responsável pelo translado das primeiras mudas de cana-de-açúcar e pela instalação do primeiro engenho na vila de Vicente, e, como se não bastasse, teria comprovado a existência de minas de ouro, prata e pedras preciosas no território brasileiro.

Sem o intento de discorrer sobre a história oficial do município e suas etapas do desenvolvimento econômico e social, retomamos rapidamente algumas intercorrências que, de alguma maneira, estão guardadas nas memórias que foram passadas de geração em geração entre os moradores de São Vicente, tais como: as intempéries e as inundações que alteraram as feições da paisagem da Vila (MADRE DE DEUS, 1975) e os infortúnios resultantes das invasões e saques de corsários piratas ingleses e holandeses, respectivamente em 1591 e 1615 (LUÍS, 1980). Tratam-se de acontecimentos que foram incorporados nas reminiscências dos vicentinos e que, vez por outra, são rememorados para enaltecer os mitos fundadores, para fomentar ações que visaram reforçar os laços de pertencimento da população residente e justificar as políticas públicas locais de tombamento de bens patrimoniais edificados e monumentos, e ainda, algumas políticas de incremento ao turismo, adotadas entre a última década do século XX e os anos iniciais do século XXI. 


\section{As políticas públicas de proteção ao patrimônio vicentino}

O Conselho de Defesa do Patrimônio Histórico, Artístico, Arquitetônico, Cultural e Turístico de São Vicente (CONDEPHASV) foi criado em 21 de outubro de 2005, em conformidade com a Lei Orgânica do Município. O decreto número 1634-A/05, assinado pelo prefeito Tércio Garcia, instituiu o conselho como "órgão autônomo e deliberativo em questões referentes à preservação e tombamento de bens culturais e naturais, vinculado à Secretaria de Turismo e Cultura".

Entretanto, passados vários meses após a fundação do CONDEPHASV, a matéria intitulada "A cidade só tem dois patrimônios", publicada pelo o jornal "A Tribuna", em 20 de maio de 2007, manifestou indignação frente à sua inoperância e a responsabilizou pelo "abandono" e a destruição do patrimônio histórico vicentino. Tal situação, interpretada nessa matéria como paradoxal e incompatível frente a aclamada distinção da cidade de São Vicente como anciã do Brasil, denunciava não haver registros efetivos de proteção dos bens culturais, históricos, naturais e paisagísticos do município na jurisprudência local.

O CONDEPHASV, então formado por vinte e dois membros, respondeu a essa provocação justificando que, apesar do levantamento dos bens a serem tombados já terem sido avaliados, o patrimônio vicentino ainda não estava tombado em função dos choques de interesses e a insatisfação daqueles que haviam se beneficiado do boom imobiliário veranista sofrido pelo município, entre as décadas de 1960 e 1970 (PELEGRINI, 2017).

Nós levantamos que a resistência dos antigos proprietários do casario da área central da cidade, por exemplo, atrasou o andamento dos processos municipais de reconhecimento dos bens patrimoniais e que o CONDEPHASV começou a anunciar o pedido de tombamento de monumentos históricos e turísticos tradicionais da cidade, somente em 2008, embora alguns bens vicentinos já tivessem sido proclamados como bens atinentes ao estado de São Paulo, na década de $1980^{4}$. 
A "Ponte Pênsil de São Vicente" e os "Remanescentes da Vila Colonial e Porto das Naus" constam da lista do Instituto do Patrimônio Histórico e Artístico Nacional (IPHAN) desde 1955. Já entre os registros efetuados pelo Conselho de Defesa do Patrimônio Histórico, Artístico, Arqueológico e Turístico do Estado de São Paulo (CONDEPHAAT) foram elencados em 1986 e 1988, respectivamente, a "Serra do Mar" e a "Casa do Barão" e sua "Cobertura Vegetal". Lamentavelmente, a maior parte do patrimônio arqueológico da cidade colonial sucumbiu à passagem do tempo e à ação das marés, portanto, muitos vestígios da primeira igreja do lugarejo e os resquícios da cultura material da população que habitou o local não foram registrados como patrimônio subaquático.

Constatamos na matéria publicada pelo jornal da baixada santista, "A Tribuna", de 06/11/2008, o anúncio do tombamento de monumentos históricos da cidade, tais como: a "Biquinha de Anchieta"; o "Marco Padrão", da praia do Gonzaguinha; a "Praça 22 de janeiro"; a "Igreja Matriz de São Vicente Mártir " e a "Ponte Pênsil"; as fachadas e/ou estruturas de algumas construções e a estatutária fixada no frontispício do prédio da Prefeitura; a "Casa" e a "Escola Martim Afonso"; o "Grupão" (escola século XIX); o Edifício Gáudio; a volumetria dos edifícios "Mirante" e "Anchieta", instalados na área central; e também, o "Jardim da Casa do Barão", o Palacete "Acastelado do Jardim Aralinda"; o "Porto das Naus", as "Ruínas do Acaraú" e o "Curtume".

No entanto, nem todos os bens supramencionados foram tombados pelo município como podemos observar no quadro que segue abaixo e, no qual, expomos o nome do patrimônio e sua localização, o ano em que ocorreu o tombamento nas esferas federal, estadual e municipal. Na maioria dos casos, notamos que a oficialização da proteção dos bens edificados se deu a partir de 2011, em dois casos apenas o acautelamento efetuado no âmbito nacional se antecipou ao municipal e ocorreu em 1955. Os cinco tombamentos promovidos pelo CONDEPHAAT foram formalizados na década de 1980. 
Sandra Pelegrini

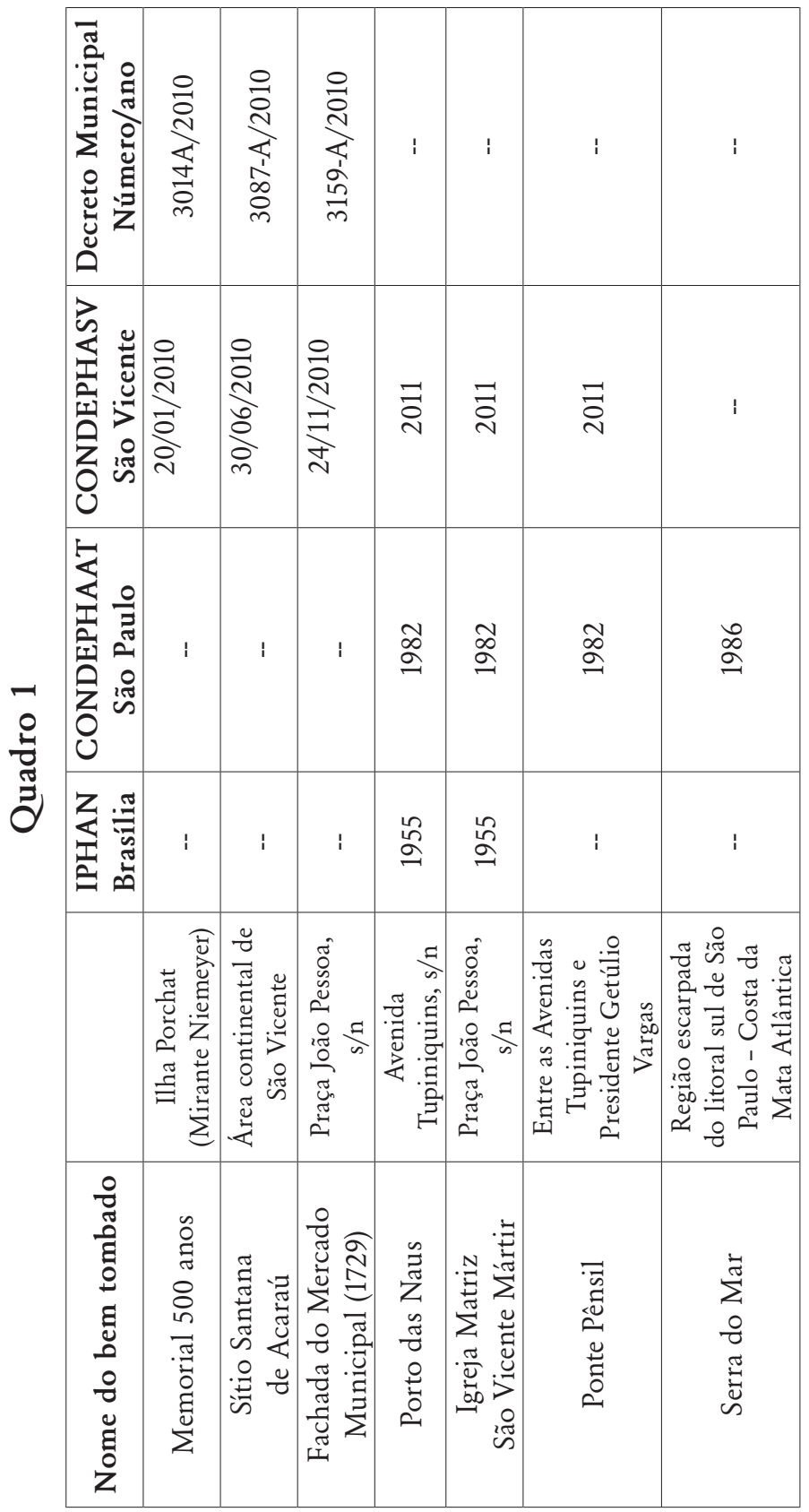

Anos 90, Porto Alegre, v. 25, n. 48, p. 87-115, dez. 2018 
Memórias e identidades: a Patrimonialização e os usos do passado

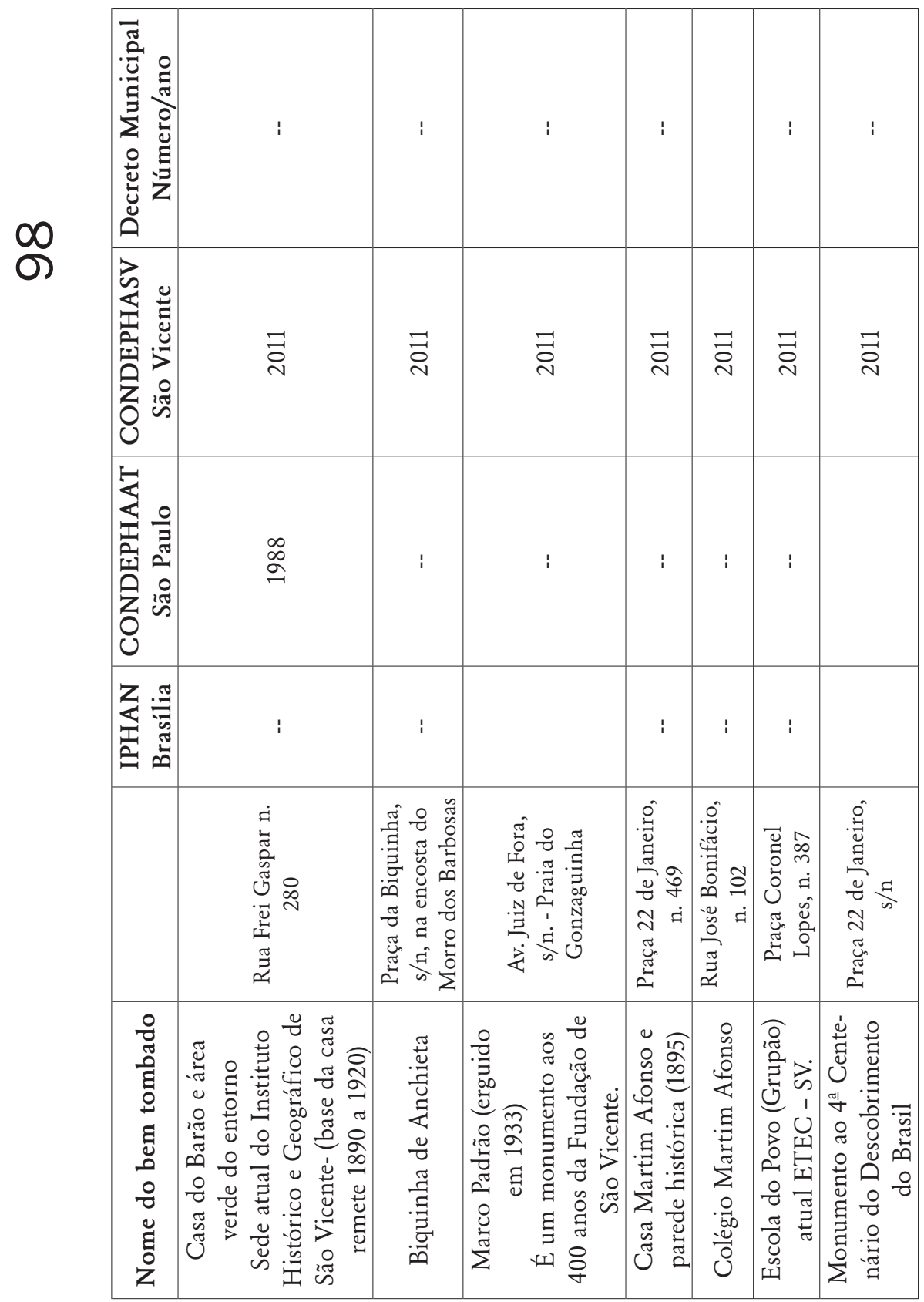

Anos 90, Porto Alegre, v. 25, n. 48, p. 87-115, dez. 2018 
Sandra Pelegrini

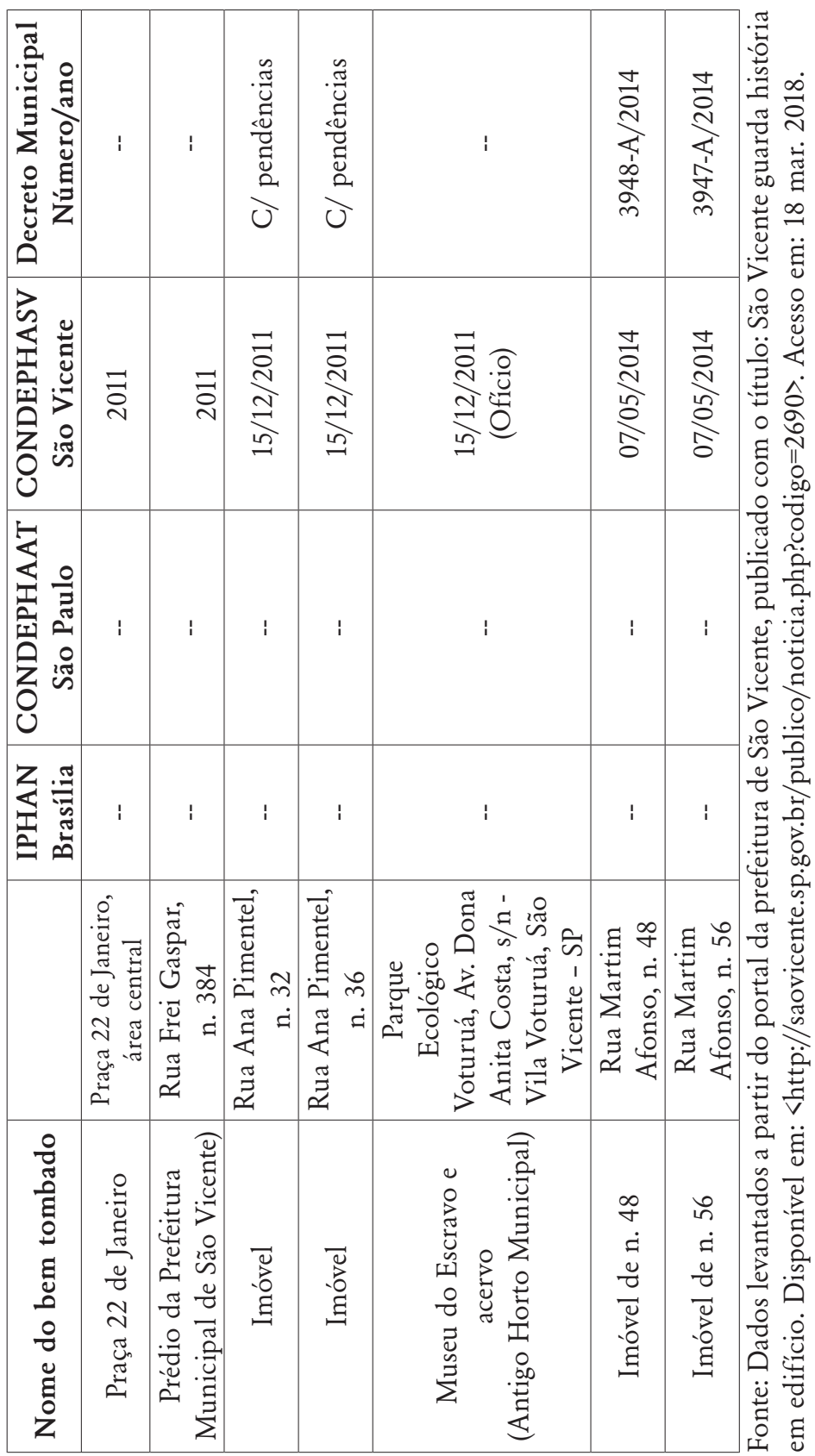


Depreendemos a partir da análise desse quadro que apenas três bens foram tombados em 2010, quais sejam: o do Sítio Santana de Acaraú, o da Fachada do Mercado Municipal (originalmente erguido em 1729) e o do Memorial 500 anos, que possui uma plataforma projetada pelo arquiteto Oscar Niemeyer e está localizado na Ilha Porchat.

Chama-nos a atenção a inexistência de alguns decretos, em especial, o relativo ao Museu do Escravo (e seu acervo), situado no Antigo Horto Municipal, atualmente denominado Parque Ecológico Voturuá, cujo ofício do Conselho de Patrimônio CONDEPHASV já solicitava providências da PMSV, em 15/12/2011, mas até o momento, não consta entre as leis municipais. Tal fato, talvez se deva, a dificuldade de reconhecimento da cultura negra por parte dos membros da CONDEPHASV. Apuramos que essa instituição museal recebeu nova nomenclatura, em 2015, quando foi transformada por segmentos da Comunidade Negra vicentina, na "Casa da Cultura Afro-Brasileira - Memorial ao Escravizado", contudo, o casario com partido arquitetônico colonial continua sem tombamento e sem conservação do seu sistema construtivo (taipa).

Observamos a ocorrência de irregulares no que diz respeito ao tombamento da Biquinha de Anchieta; da Casa Martim Afonso e da base da parede histórica da residência, erguida em 1895; do Colégio Martim Afonso; da Escola do Povo, conhecida por Grupão; do Marco Padrão, um monumento edificado em 1933, para celebrar os 400 anos da Fundação de São Vicente; do Monumento ao 4⿳亠丷厂 Centenário do Descobrimento do Brasil (1900); e do Prédio da Prefeitura Municipal de São Vicente. Todos são referenciados nas intenções de tombamento por parte do conselho supracitado e mencionados nos jornais da Baixada Santista pesquisados. Sem dúvida, a motivação para essa dificuldade certamente não seria a mesma que detectamos em relação ao Museu dos Escravos, pois se tratam de alusões a personagens conhecidos da história brasileira, marcos oficiais e efemérides.

Os edifícios situados à Rua Ana Pimentel, números 32 e 36 , ainda não foram reconhecidos como bens tombados porque existem pendências na documentação, decorrentes de problemas na 
jurisprudência. Provavelmente, cairão literalmente por terra antes que qualquer providência seja tomada, pois passaram por reformas devastadoras e não foram conservados. Eles já sofreram tantas alterações ao longo desse período que, provavelmente, os impeça de se enquadrarem nos requisitos necessários para o tombamento dos bens materiais ${ }^{6}$.

O Conselho até o momento pouco atuou em prol da proteção dos bens ambientais e paisagísticos da cidade, é precária a situação das encostas que cercam o município e visível a poluição da maioria das praias e dos rios, a falta de cuidado com as matas ciliares. Entre o patrimônio natural tombado pelo CONDEPHAAT e pelo IPHAN, constam apenas a Serra do Mar e a Mata Atlântica.

Posto isto, consideramos de fundamental importância frisarmos que o sentido de pertença e, sobretudo, os vínculos entre as identidades locais e os patrimônios tendem a se estreitar no momento em que o tombamento se torna uma maneira dos habitantes recriarem simbolicamente a sua relação com a cidade, com sua paisagem natural e cultural, ou seja, quando eles conseguem reconhecer suas memórias coletivas e individuais como parte integrante desses bens, independentemente de sua tipologia. A recriação da "Primeira Vila do Brasil", em 2001, que passaremos a discutir, daria conta de restabelecer esses laços de pertencimento?

\section{As invenções do patrimônio}

A partir de 1997, notamos certa inquietação por parte das autoridades municipais e das elites residentes em São Vicente no tocante a implementação de políticas de desenvolvimento, associadas às medidas de proteção e invenção do patrimônio ${ }^{7}$, simultaneamente, articuladas com exploração dos atrativos turísticos que previam a criação de opções de entretenimento e lazer para os veranistas que visitavam a cidade. A tática, tal qual se refere Certeau (1998), era de restabelecer as interfaces entre o turismo e a "vocação histórica" da cidade, reiteradas vezes aludida como a primeira e mais antiga 
cidade do Brasil. Para tanto, foi acionado o marketing cultural que tomou o turismo como uma solução plausível para os problemas do desenvolvimento econômico e da geração de emprego e renda em São Vicente e o transformou em alvo de investimentos das elites políticas e dos segmentos comerciais. Outdoors e adesivos nos carros da prefeitura e no transporte coletivo passaram a exibir frases como: "São Vicente - a primeira sempre", "A Primeira Câmara das Américas", "Berço da Democracia nas Américas", entre outros bordões que também foram difundidos por meio das narrativas da imprensa local, ganharam destaque considerável nos discursos do prefeito e dos vereadores, nas ações das empresas turísticas.

Estas últimas providenciaram a instalação de equipamentos para arborismo e "pesque-pague", realizaram investimentos em um programa no canal de TV a cabo, intitulado "TV - Primeira", bem como "painéis eletrônicos de informações turísticas", disponibilizados em praças e avenidas. $\mathrm{Na}$ área central da urbe, espaços abertos e largos foram equipados, reformados e revitalizados para receber feiras náutico-esportivas (ROQUE, 2017).

A expressão "Aqui nasceu o Brasil", deveras realçada pela mídia à época das celebrações do 22 de abril de 2000 e no decorrer das festividades cívicas dos 500 anos do descobrimento, impulsionou a produção de camisetas e toda espécie de suvenires com vistas a articular o patrimônio natural e paisagístico de São Vicente ao seu passado histórico. Esse é o caso do logotipo de uma caravela, utilizado em representações imagéticas formatadas em metal dourado que ponteavam os extremos das placas de sinalização e de identificação dos lugares turísticos, das praias, do centro cívico e do comércio local, dispostas pelos espaços de circulação da urbe e nas áreas do entorno, nas vias de acesso à cidade.

À criação do símbolo visual da nau, somou-se a inserção das letras "S V" sobre o desenho estilizado de ondas, de modo a promover uma intervenção dialética e identitária do conjunto impresso por meio de "adesivos estampados nos veículos oficiais, nas camisetas dos garis, em painéis afixados nos espaços destinados à realização de eventos e nos cestos de lixo distribuídos ao longo das praias" (ROQUE, 2002, p. 4). A exibição ostensiva dessas simbologias 
repercutiu nas entrevistas dos prefeitos e dos secretários municipais, nas matérias impressas em jornais e revistas, nos programas transmitidos pelas emissoras de rádio e televisão, nas imagens e nos textos digitais veiculados pela Internet.

No período subsequente, mais precisamente em 2001, foi inaugurado o "Parque Cultural Vila de São Vicente", localizado nas imediações da Igreja Matriz, situada na Praça João Pessoa, e que segundo a Prefeitura Municipal de São Vicente (PMSV), reproduzia "[...] a arquitetura, usos e costumes da Primeira Cidade Brasileira, colonizada por portugueses”. Nesse parque temático, os visitantes teriam a oportunidade de "conhecer o cotidiano colonial do século XVI, em diversos espaços culturais" que reverenciavam "importantes personagens da história vicentina e brasileira na região" (PMSV, 2014).

Na Figura 1, observamos o quão cuidadosas foram as reproduções dos referenciais coloniais na arquitetura e no designe dos móveis que compõem o cenário recriado na Vila de São Vicente:

Figura 1 - Parque Cultural Vila de São Vicente

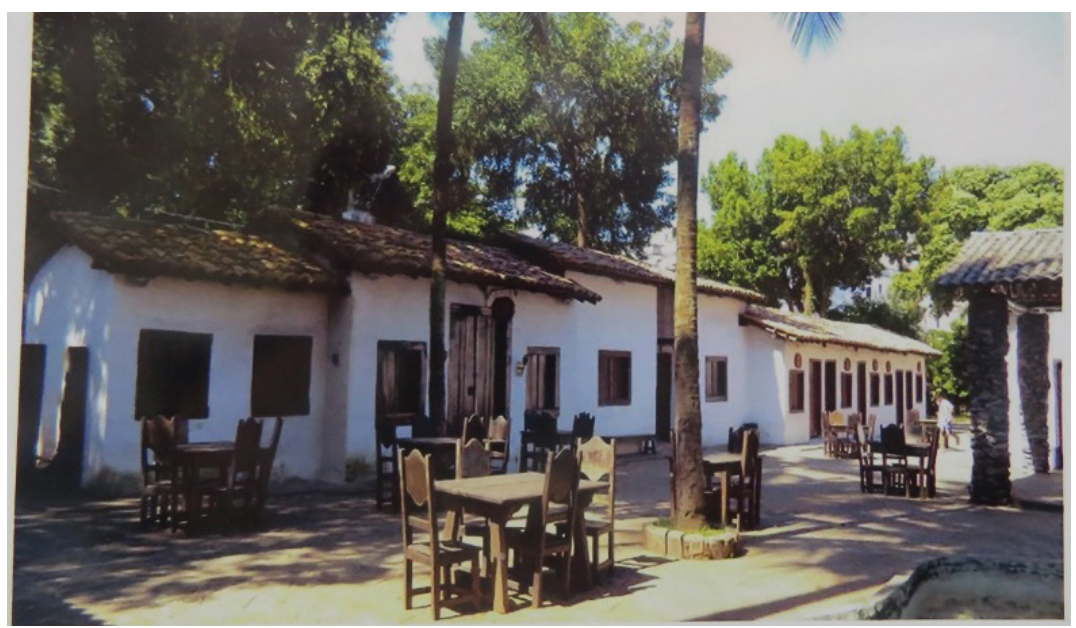

Fonte: Galeria de fotos da Prefeitura Municipal de São Vicente. Disponível em: 〈http://saovicente.sp.gov.br/galerias/visualizargaleria.asp?ID=21>. Acesso em: 2 mar. 2018. 
Por meio de grupos teatrais e roteiro previamente definido pela prefeitura, atores revezavam-se narrando a história da fundação da cidade, declamando poesias, comentando fatos do dia-a-dia dos antigos vilarejos coloniais, recriando conversas entre comadres e encontros ocasionais com indígenas catequizados pelos jesuítas e padres.

À época de sua inauguração, o parque, administrado pela Associação de Desenvolvimento Econômico e Social das Famílias (ADESAF), granjeou inúmeras apreciações críticas dos estudiosos do patrimônio, pois os seus gestores tendenciosamente articularam a ideia de autenticidade à ideia da reprodução das peculiaridades estéticas e históricas da arquitetura e do traçado da antiga vila, sem nenhuma referência aos pescadores e com a inserção de lago artificial, guarda-sóis, entre outros anacronismos.Ademais, a pressuposta concepção do parque como um lugar capaz de reavivar as memórias da população residente e dos visitantes mostrava-se duplamente dissimulada: primeiro, porque ele se constituía como um simulacro das histórias oficiais; e segundo, porquanto se assentava em um projeto hierarquizante de acesso à cidade, pautado por uma velada proposta de distinção e de exclusão social agravada em 2010, mediante a adoção do "Passaporte Turístico", lançado pela Secretaria de Turismo da cidade (PELEGRINI, 2017, p. 24).

O cenário, literalmente cercado (Figura 2), mostra-se impregnado de explicações distorcidas e de representações dicotômicas das relações humanas, das noções de progresso e civilidade versus a de atraso e ignorância, expressas na comparação inadequada entre a cultura do colonizador europeu e a da população indígena e mameluca. A construção cenográfica apresenta juízos de valor que favorecem e induzem a supressão das percepções referentes ao aniquilamento da população indígena e reforçam, como assinalamos, as equivocadas acepções de cultura e poder. 
Figura 2 - Entrada do Parque Cultural Vila de São Vicente

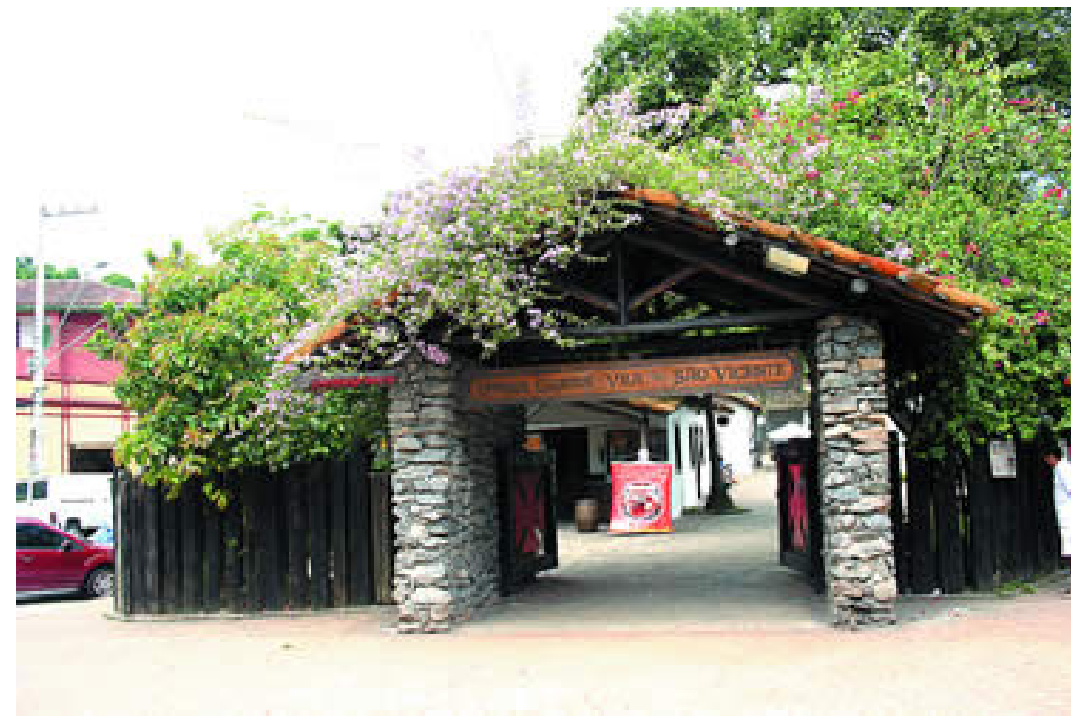

Fonte: Galeria de fotos da Prefeitura Municipal de São Vicente. Disponível em: <http://saovicente.sp.gov.br/galerias/visualizargaleria.asp?ID=21/>. Acesso em: 2 mar. 2018.

Cumpre-nos assinalar que as obras não passaram pela avaliação dos técnicos do Instituto do Patrimônio Histórico Artístico Nacional (IPHAN) e que o parque foi concluído com advertências de embargos e de ultimatos de interdição por infringir as determinações da Lei Federal Tombamento (25/1937), no que tange ao desrespeito à volumetria da Igreja Matriz São Vicente Mártir, tombada pelo IPHAN em 1955 e pelo CONDEPHAAT, em 1982. Em outras palavras, a construção do parque temático transgrediu as normativas de proteção dos bens sob a tutela e salvaguarda do Estado brasileiro. 
Scocuglia, ao comentar a arquitetura cenográfica, chama a atenção para dois perigos principais desse tipo de "reconstrução": o da transformação dos "indivíduos" em "meros contempladores unidimensionais" e o da "[...] valorização artificial do solo urbano, associada a uma ampliação do fluxo de pessoas nas áreas criadas dentro das propostas de geração de espaços públicos parciais” (2006, p. 1-2).

A propósito, nos períodos próximos aos preparativos das festas de celebração do aniversário do município, salta aos olhos dos observadores a nítida disseminação dos slogans mencionados. "A Primeira Sempre", entre outras frases similares, continua sendo utilizada como marketing cultural e empresarial, impresso na pintura dos veículos responsáveis pelo transporte coletivos e privado, nos caros de aluguel que conduzem os veranistas e demais passageiros pela urbe.

Antes de partimos para a considerações finais, não podemos deixar de mencionar que "Encenação da Fundação da Vila de São Vicente", concebida por iniciativa de grupos de teatro amador da cidade, em 1982, para comemoração dos 450 anos da fundação da cidade e que poderia alçar a condição de um bem imaterial vicentino, também passou por um intenso processo de espetacularização que, em última instância, implicou recriações e apropriações que produziram efeitos devastadores.

A caracterização dos povos indígenas e dos portugueses nos anos oitenta do século XX, nos chama a atenção, pois tendia aos excessos das imagens estereotipadas, ora idílicas, ora tragicômicas. Nesses espetáculos, a figura dos primeiros aproximava-se das representações dos índios estadunidenses, nos filmes hollywoodianos; enquanto os heróis portugueses, apesar de todos os infortúnios das longas viagens marítimas, eram distinguidos pela nobreza de seus atos e de sua indumentária ${ }^{8}$.

Dezesseis anos depois, em 1998, o espetáculo já havia tomado outras proporções a ponto de suscitar parcerias entre os setores públicos e privados para custear as obras de construção de uma arena na praia de Gonzaguinha, onde supostamente havia desembarcado o fundador da cidade. O cenário já não era mais improvisado e os 
principais atores da cidade tinham sido substituídos por intérpretes famosos, contratados no auge do sucesso na televisão brasileira. A encenação da história da chegada de Martim Afonso passava a ser exibida, pela primeira vez, no período noturno e retirada das mãos da população residente, cujo papel passou de protagonista à figurante 9 .

A partir da sua inclusão na lista do Livro dos Recordes Guinness (2002) como o "maior espetáculo teatral em areia de praia do mundo", o evento adquiriu dimensões inimagináveis. Passados mais cinco anos, ele foi integrado ao circuito turístico do balneário e recebeu alguns aditivos, tais como: a inclusão de show pirotécnico e da caravela "Espírito Santo"

Em 2007, o "show" obteve repercussão nacional e passou a ser exibido em partes, divido em atos, durante sete dias; recebeu um público com cerca de 56 mil pessoas; contou com a participação de 1.300 atores coadjuvantes da comunidade e de atores de emissoras de televisão como a Rede Globo e a TV Record ${ }^{11}$.

O gigantismo da trigésima segunda edição de "A Fundação da Vila de São Vicente", realizada na segunda quinzena do mês de janeiro de 2014, com presença dos atores Oscar Magrini e Armando Babaioff na interpretação de Martim Afonso e Tibiriçá, surpreendeu porque a montagem reuniu cinco mil pessoas e, conforme os dados da prefeitura, veiculados na imprensa e em meios digitais, o elenco organizado em grupos ensaiou por aproximadamente oito meses ${ }^{12}$.

Verificamos que a participação da população residente foi relegada a um plano secundário, tanto na encenação da peça teatral, como na concepção do "Parque Cultural Vila de São Vicente". $\mathrm{Na}$ primeira, os atores locais foram substituídos e os munícipes assumiram apenas os papeis de figurantes; no segundo, os saberes de ofício da pesca sequer foram referenciados e as técnicas de preparação dos alimentos como a cocada caiçara foram ignoradas. Os proprietários dos restaurantes, sorveterias e lojas de doces optaram pela cozinha internacional, eles não aventaram sequer a possibilidade de contemplar aspectos da culinária indígena ou luso-brasileira - uma postura que evidencia o "desconhecimento" de parte do patrimônio culinário vicentino. 
A "senhorinha da cocada" e o "tio do milho verde cozido" ficaram para fora das instalações do parque, assim como os seus quitutes. Nos casos da encenação teatral e no espaço do parque, os saberes e competências foram confiados para outras pessoas e, novamente, a população foi paulatinamente excluída em nome do marketing turístico, venerador dos "atores globais" e dos "chefes" autorizados.

Devemos admitir que a grandiosidade das edições provocou certa euforia entre os munícipes, atraíram muitos turistas e geraram emprego e renda para parte da população envolvida na confecção do vestuário, empregada na iluminação e nos serviços de limpeza. Mas, essa imponência causou descontinuidades na exibição do espetáculo no início da década de 1990 e no ano 2016 - quando essa montagem foi orçada pela administração municipal em um montante de 3,3 milhões de reais ou 13,2 milhões de dólares. Nas duas ocasiões a Prefeitura Municipal de São Vicente alegou não ter recursos financeiros e não poder contar com verbas federais e estaduais para a empreitada. As crises econômicas e políticas vivenciadas pelo país nos últimos anos também restringiram o auxílio financeiro do Governo de Dilma Rousseff e o patrocínio de empresas estatais e privadas.

Curiosamente, a matéria "São Vicente completa 484 anos", publicada pelo jornal "Gazeta de S. Paulo", em 22 de janeiro de 2016, saudou a realização da peça teatral de "forma não oficial", no Instituto Histórico e Geográfico de São Vicente, mais precisamente nos "jardins da Casa do Barão", com o "apoio de grupos de arte e moradores da cidade". Dessa vez, duzentos atores da comunidade reassumiram seus papéis e o médico e músico da cidade, Henrique Marques, personificou a figura de Martin Afonso de Souza, sob a direção de "comando" de Roberto Marchese, o mesmo diretor responsável pela primeira edição do espetáculo na praia, em 1982.

$\mathrm{Na}$ atualidade, o parque temático da Vila, como é conhecido, não atrai mais tantos visitantes, estabelecimentos comerciais fecharam e a Praça João Pessoa está abandonada à própria sorte, tanto quanto a população de risco que a habita. São muitas as reclamações de falta de segurança por parte dos moradores, veranistas e demais transeuntes ocasionais que circulam no local. 
Diante do exposto, reiteramos que os bens culturais e os equipamentos urbanos são conservados e preservados quando realmente integram a dinâmica da cidade e as políticas públicas municipais, quando são apropriados pela população residente ou por habitantes eventuais, como os veranistas.

\section{Considerações finais}

A preservação e a salvaguarda do patrimônio, sem dúvida, propiciam a apropriação simbólica de grupos representativos de segmentos socais distintos, independentemente da natureza ou tipologia dos bens protegidos. Porém, o desenvolvimento de projetos de conservação, a implantação de leis e decretos de tombamento e de registro dos bens, de nada valem se o sentido de pertença não estiver enraizado na alma da população residente (PELEGRINI, 2009; 2017).

Nessa direção, as proposições relativas à "conservação integrada”, postuladas por Laenen (1997) coadunam-se a ideia aqui defendida: quando a população é estimulada a participar das ações de proteção, a "personalidade cultural" pode ser preservada, mesmo diante da mundialização das informações (globalização) ou das crises econômicas.

Apesar da abordagem crítica ora apresentada, julgamos necessárias as articulações entre as políticas públicas de cultura e as de desenvolvimento de atrativos turísticos, as ações de proteção e salvaguarda dos bens patrimoniais e os investimentos empresariais na esfera cultural (BARRETO, 2007). Todavia, não podemos ignorar as interferências dos turistas na manutenção e na transformação das culturas tradicionais receptoras, uma vez que as fronteiras culturais são fluidas, dinâmicas e multifacetadas, como sugerem Homi Bhabha (2013) e Nestor García Canclini (2006; 2013).

No caso de São Vicente, detectamos que as políticas públicas municipais e estaduais, além de não promoverem a conservação dos bens naturais, paisagísticos e históricos da cidade, não levaram em 
consideração as questões mencionadas pelos autores supracitados: o empresariado, os trabalhadores, as crianças, os jovens e os adultos não foram envolvidos em projetos de Educação Patrimonial ou em programas de conscientização sobre a imperiosa necessidade de proteção de edifícios antigos e da floresta, tampouco das matas ciliares, dos rios ou das praias, o que resultou em ambientes degradados.

De modo similar, não foram valorizadas as práticas tradicionais, os saberes de ofício da pesca ou da preparação dos alimentos consumidos pelas comunidades - potenciais bens culturais intangíveis a serem salvaguardados para as futuras gerações. $\mathrm{O}$ caso do Museu dos Escravos, transformado em Casa da Cultura Afro, evidencia que existem demandas no sentido da patrimonialização de bens culturais tangíveis e intangíveis de distintas origens étnicas, porém, o registro dos bens patrimoniais concentrou-se na materialidade dos edifícios oficiais e dos monumentos que representam principalmente a cultura ocidental.

As identidades de vários grupos teriam se perdido ao longo do tempo no município de São Vicente ou as autoridades políticas e os membros do Conselho do Patrimônio, o CONDEPHASV, estão com dificuldade para ouvir os seus clamores? Esta indagação continua sendo alvo de pesquisa teórica, metodológica e empírica. Ela com certeza será enfrentada em outra oportunidade.

\section{MEMORIES AND IDENTITIES: PATRIMONIALIZATION AND THE USES OF THE PAST}

Abstract: This article, instigated by the proposals of the dossier "History and Heritage: theoretical and methodological questions", analyzes the concept of patrimonialization and the invention of spaces of memory associated with public policies for the protection of cultural goods and tourism. On the one hand, it seeks to detect the dangers that surround the professionals of the Human Sciences and of the Social and Applied Sciences that act in commissions or councils that aim the safeguard of the patrimonial assets. And, on the other hand, it establishes the theoretical and methodological connections to problematize the question of the tipping and registration of patrimonial, tangible and intangible assets in the São Vicente Beach Resort, located on the coast of São Paulo, Brazil. The option for the epistemological debate articulated to the 


\section{Sandra Pelegrini}

empirical is relevant, since it offers subsidies for the reflections on the social responsibility of the researchers that integrate commissions and councils, to which the power of decision is instituted to elect patrimonial property or to condemn it to oblivion and undoing.

Keywords: Patrimonialization. Public policy. Memory spaces.

\section{Notas}

${ }^{1}$ Essa pesquisa vem sendo desenvolvida desde 2016, para cumprir os requisitos de Tempo Integral e dedicação exclusiva na universidade onde a investigadora está lotada. Ao longo de sua realização, contou com o financiamento da Fundação Araucária e da Secretaria de Estado da Secretaria da Ciência, Tecnologia e Ensino Superior (SETI/PR).

${ }^{2}$ A ONU, a Unesco e o ICOM são organizações criadas após a II Guerra Mundial que mantém relações oficiais entre si.

${ }^{3}$ A Vila de São Vicente foi fundada oficialmente fundada em 22 de janeiro de 1532, por Martim Afonso de Sousa, um fidalgo nomeado donatário de duas capitanias hereditárias pelo rei Dom João III (LEME, 2003; PELEGRINI, 2017).

${ }^{4}$ A matéria publicada pelo jornal A Tribuna, de 6 de novembro de 2008 (página A-11), comenta as ações do Conselho de Patrimônio de São Vicente.

${ }^{5} \mathrm{Na}$ matéria "Museu dos Escravos será Casa da Cultura Afro em São Vicente", publicada pelo G1, de 19/11/2014, encontramos mais detalhes sobre a criação da nova instituição cultural. Disponível em: <http://g1.globo.com/sp/santos-regiao/ noticia/2014/11/museu-dos-escravos-sera-casa-da-cultura-afro-em-sao-vicente-sp. html>. Acesso em: 12 jan. 2017.

${ }^{6} \mathrm{Na}$ imagem atualizada da fachada do edifico número 32, da Rua Ana Pimentel, no centro de São Vicente, são visíveis as alterações referidas.

${ }^{7}$ Tomamos a invenção do patrimônio como uma tática (Cf. CERTEAU, 1998) e uma prática comum aos Estados nacionais, considerada capaz de representar, simbolicamente, uma nação e de instigar o desenvolvimento do "espírito coletivo de pertencimento" (ANDERSON, 2008).

${ }^{8} \mathrm{~A}$ análise superficial do espetáculo deve-se ao fato de não constituir o objetivo principal dessa reflexão. Mas, a observação do cenário, da indumentária, da caracterização dos personagens e diálogos indicam que o assunto merecerá aprofundamento crítico em outra ocasião. 
${ }^{9}$ As imagens da vista aérea da arena da Praia de Gonzaguinha e do espetáculo noturno podem ser consultadas nos arquivos da rádio CBN da cidade de Santos. Disponível em: 〈http://cbnsantos.com.br/>. Acesso em: 12 jan. 2015 e nos arquivos do Jornal Vicentino. Disponível em: <http://jornalvicentino.com.br/>. Acesso em: 12 jan. 2015, respectivamente.

${ }^{10}$ Uma fotografia da réplica dessa embarcação, batizada como "Espírito Santo", pode ser visualizada no site do Jornal Vicentino. Disponível em: <http://jornalvicentino.com.br>. Acesso em: 15 jan. 2015.

${ }^{11}$ Alexandre Borges, Ary Fontoura, Bianca Rinaldi, Bete Mendes, Cecil Thiré, Francisco Cuoco, Humberto Martins, Isadora Ribeiro, John Herbert, Júlia Lemmertz, Malvino Salvador, Marcos Pasquim, Mauro Mendonça, Ney Latorraca, Nuno Leal Maia, foram alguns dos atores contratados.

${ }^{12}$ Conforme informações publicadas no site da Secretaria de Cultura da Prefeitura (PMSV) e empresas de turismo. Disponível em: <http://notícias.bol.uol. com.br>. Acesso em: 16 jan. 2014.

\section{Referências}

ANDERSON, Benedict. Comunidades imaginadas: reflexões sobre a origem e a Difusão do nacionalismo. São Paulo: Companhia das Letras, 2008.

A TRIBUNA. A cidade só tem dois patrimônios. Santos, SP, 20 maio 2007. . 6 nov. 2008. p. A-11.

BARRETO, Margarita. Cultura e Turismo: discussões contemporâneas. Campinas: Papirus, 2007.

BHABHA, Homi. O Local da Cultura. Belo Horizonte: Editora da UFMG, 2013. BRASIL. Conselho de Defesa do Patrimônio Histórico, Artístico, Arquitetônico, Cultural e Turístico de São Vicente (CONDEPHASV). Lei 1634/05. Disponível em: 〈https://cm-sao-vicente.jusbrasil.com.br/legislacao/710539/lei-1634-05>. Acesso em: 19 nov. 2018.

CANCLINI, Nestor García. Consumidores e Cidadãos: Conflitos Multiculturais da Globalização. Rio de Janeiro: Editora da UFRJ, 2006.

. Culturas híbridas: estratégias de entrar e sair da modernidade. São Paulo: Ed. USP, 2015.

CANDAU, Joel. Memória e identidade. São Paulo: Contexto, 2011.

Anos 90, Porto Alegre, v. 25, n. 48, p. 87-115, dez. 2018 
. Um odor desconcertante na casa de Tia Léonie. In: SCHIAVON, Carmem; PELEGRINI, Sandra C. A. (Org.). Patrimônios plurais: iniciativas e desafios. Rio Grande: Editora da FURG, 2016.

CENAS com diálogos de época retornam ao Parque Cultural Vila de São Vicente. Jornal Vicentino. Disponível em: 〈http://jornalvicentino.com.br/v2/ cenas-com-dialogos-de-epoca-retornam-ao-parque-cultural-vila-de-sao-vicente $\rangle$. Acesso em: 18 mar. 2018.

CERTEAU, Michel de. A invenção do cotidiano. Artes de Fazer. Petrópolis: Vozes, 1998.

Choay, Françoise. A Alegoria do Patrimônio. Tradução de Teresa Castro. Lisboa: Edições 70, 2001.

GAZETA DE SÃO PAULO. São Vicente completa 484 anos. São Paulo, 22 jan. 2016.

GIANESELLA, Rubens. Gêneses urbanas do colonialismo: síntese de encontros culturais. Anais do Museu Paulista, São Paulo, v. 20, p. 165-200, 2012. Disponível em: 〈http://scielo.br/pdf/anaismp/v20n1/v20n1a07.pdf〉. Acesso em: 10 abr. 2015.

G1. Museu dos Escravos será Casa da Cultura Afro em São Vicente. G1, São Paulo, 19 nov. 2014. Disponível em: <http://g1.globo.com/sp/santosregiao/noticia/2014/11/museu-dos-escravos-sera-casa-da-cultura-afro-em-sao-vicente-sp. html >. Acesso em: 12 jan. 2017.

INSTITUTO BRASILEIRO DE GEOGRAFIA E ESTATÍSTICA (IBGE). População de São Vicente. Disponível em: <https://cidades.ibge.gov.br/brasil/sp/ sao-vicente/panorama>. Acesso em: 4 jan. 2018.

JACOBI, Pedro Roberto. Educação Ambiental: o desafio da construção de um pensamento crítico, complexo e reflexivo. Educação e Pesquisa, São Paulo, v. 31, n. 2, p. 233-250, maio/ago. 2005. Disponível em: <http://scielo.br/pdf/ ep/v31n2/a07v31n2.pdf>. Acesso em: 17 mar. 2018.

JORNAL VICENTINO. Disponível em: 〈http://jornalvicentino.com.br $>$. Acesso em: 1 maio 2016.

LAENEN, M. Centre International d'Études pour la Conservation et la Restauration des Biens Culturels. ICCROM chronique, Roma, n. 24, 1997.

LEME, Pedro Taques de Almeida. História da Capitania de São Vicente. Brasília, DF: Edições do Senado Federal, 2003.

LÉVI-STRAUSS, Claude. Tristes Trópicos. São Paulo: Anhembi, 1957.

LUÍS, Washington. Na capitania de São Vicente. São Paulo: Edusp, 1980.

Anos 90, Porto Alegre, v. 25, n. 48, p. 87-115, dez. 2018 
MADRE DE DEUS, Frei Gaspar da. Memórias para a história da Capitania de São Vicente. Belo Horizonte: Itatiaia; São Paulo: Edusp, 1975.

MOTTA, Lia; THOMPSON, Analucia. Entorno de bens tombados. Rio de Janeiro: IPHAN/DAF/Copedoc, 2010.

PELEGRINI, Sandra C. A. Patrimônio Cultural: Consciência e preservação. São Paulo: Brasiliense, 2009.

. Turismo \& Patrimônio em tempos de globalização. Campo Mourão, PR: Editora FECILCAM, 2010.

Negligence and reinvention: cultural heritage of the waterling place of São Vicente (São Paulo, Brazil). In: CUNHA, Fabiana L.; SANTOS, M.; RABASSA, J. (Org.). Latin American Heritage. Interdisciplinary Dialogues on Brazilian abd Argentinian Case Studies. Springer, 2017, v. 1, p. 21-31.

PREFEITURA Municipal de São Vicente. Disponível em: <http://saovicente. sp.gov.br/>. Acesso em: 19 jul. 2014.

PROCESSO 0514-T-51. Inscrição n. 308, Livro do Tombo Histórico/IPHAN. Inscrição n. 162, p. 36, 30/5/1982 (Remanescentes da Vila Colonial e Porto das Naus).

PROCESSO 20868/79. Tomb.: Res. 40 de 6/6/85. D.O.: 15/6/85. Livro do Tombo Arqueológico, Etnográfico e Paisagístico: Inscrição n. 16, 8/9/1986 (Serra do Mar). p. 305.

PROCESSO 20853/79. Tomb.: Res. 29 de 6/6/88. D.O.: 7/6/88. Livro do Tombo Histórico: Inscrição n. 279, 18/7/1988. (Casa do Barão e Cobertura Vegetal). p. 72. PROCESSO 21825/81. Tomb.: Res. 20 de 30/4/82. D.O.: 5/5/82. Livro do Tombo Histórico: Inscrição n. 175, 26/5/1982 (Ponte Pênsil de São Vicente). p. 41.

ROQUE, Irene Tulik Mariano. Efeitos de ações públicas na imagem turística de uma localidade: São Vicente revelada nos clippings. Dissertação (Mestrado em Ciências da Comunicação)-ECA, Universidade de São Paulo, São Paulo, 2002.

. Efeitos de ações públicas na imagem turística de São Vicente. Revista Eletrônica Patrimônio: Lazer \& Turismo, Santos, SP, 2005. Disponível em: $<$ http://unisantos.br/pos/revistapatrimonio/artigosfe96.html/>. Acesso em: 15 dez. 2017.

SÃO VICENTE festeja os seus 450 anos. Jornal Cidade de Santos, Santos, SP, 23 jan. 1982. 
SCOCUGLIA, Jovanka Baracuhy Cavalcanti. A insustentável leveza do patrimônio cultural: memória e marketing. Revista Eletrônica Patrimônio: Lazer \& Turismo, Santos, SP, 2006. Disponível em: <http://unisantos.br/pos/revistapatrimonio/>. Acesso em: 15 jun. 2015.

UNESCO. Conferência Mundial sobre as Políticas Culturais. Mondiacult (México). Disponível em: $<$ http://portal.iphan.gov.br/uploads/ckfinder/arquivos/ Declaracao\%20do\%20Mexico\%201985.pdf>. Acesso em: 19 nov. 2018.

Recebido em: 30/04/2018

Aprovado em: 20/08/2018 
